João Paulo Theophilo Di Benedette

\title{
Caracterização molecular das subunidades catalítica e regulatória da calcineurina no fungo patogênico Paracoccidioides brasiliensis
}

Dissertação apresentada ao Departamento de Parasitologia do Instituto de Ciências Biomédicas da Universidade de São Paulo, para obtenção do Título de Mestre em Ciências.

Área de concentração: Biologia da Relação Patógeno-Hospedeiro

Orientadora: Prof. Dr. Claudia Barbosa Ladeira de Campos

Co-orientador: Prof. Dr. Francisco Gorgônio da Nóbrega 
DI BENEDETTE, J.P.T. Caracterização molecular das subunidades catalítica e regulatória da calcineurina no fungo patogênico Paracoccidioides brasiliensis. 2009. 85 pg. Dissertação (Mestrado. Instituto de Ciências Biomédicas da Universidade de São Paulo, São Paulo, 2009.

O fungo Paracoccidioides brasiliensis é o agente etiológico da paracoccidioidomicose, uma micose endêmica da América Latina, e uma das principais micoses sistêmicas prevalentes no Brasil, Colômbia e Venezuela. Este é um fungo dimórfico, cujo dimorfismo da forma de micélio saprofítico para a de levedura infectiva está profundamente relacionado à virulência. Assim como em outros fungos, a fosfatase calcineurina, controla o dimorfismo no $P$. brasiliensis e, acredita-se, outras propriedades importantes para a infecção e virulência. Neste trabalho foi caracterizada a estrutura gênica e expressão dos genes que codificam para subunidades A (PbCNA) e B $(P b C N B)$ da calcineurina do isolado $\mathrm{Pb} 18$ de $P$. brasiliensis como parte do esforço para verificar o papel do sistema $\mathrm{Ca}^{2+} /$ calmodulina/calcineurina na transição dimórfica, crescimento e metabolismo deste fungo. A seqüência nucleotídica de PbCNA compreende uma ORF de 1802 pb dividida em 4 exons, que codifica uma proteína de 536 aa e possui massa molecular igual a 61,6 kDa. PbCNB compreende uma ORF de 862 pb também dividida em 4 exons, que codifica para uma proteína composta de 201 aa e massa molecular de 19,6 kDa. PbCNA, e em menor escala também PbCNB, apresentaram aumento dos níveis de transcritos nas fases inicias (até 1 hora) da transição micélio-levedura (M-L) induzida por aumento de temperatura, o que sugere a necessidade da calcineurina para o desencadeamento da transição dimórfica em resposta ao choque térmico. Os transcritos de ambos os genes mostraram-se mais elevados em leveduras do que em micélios, o que pode estar relacionado com a maior virulência das formas que crescem a $37{ }^{\circ} \mathrm{C}$. Genes cujos produtos poderiam interagir com calcineurina foram buscados no transcriptoma do isolado $\mathrm{Pb} 18$ através de ferramentas computacionais, o que forneceu um resultado bruto de 841 genes. Os perfis de expressão durante o dimorfismo M-L de três deles, COX1, CCH1 e AOX1, acompanham os perfis de PbCNA e PbCNB. Ensaios de expressão heteróloga indicaram que $P b C N A$ não é capaz de complementar funcionalmente mutantes de Saccharomyces cerevisiae nos quais as duas cópias da subunidade $A$ da calcineurina que este organismo possui foram deletadas. Como conclusão, a caracterização dos genes e regiões adjacentes das subunidades A e B da calcineurina, sua expressão nas diferentes formas e ao longo do dimorfismo, assim como análises de expressão heteróloga podem contribuir para o entendimento dos processos bioquímicos envolvidos na transição morfológica e no desenvolvimento da patogenicidade e virulência do $P$. brasiliensis.

Palavras-Chave: Paracoccidioides brasiliensis. Dimorfismo. Calcineurina. Expressão gênica. 
DI BENEDETTE, J.P.T. Molecular characterization of catalytic and regulatory subunits of calcineurina in the pathogenic fungus Paracoccidioides brasiliensis. 2009. 85 p. Master thesis. Instituto de Ciências Biomédicas da Universidade de São Paulo, São Paulo, 2009.

The fungus Paracoccidioides brasiliensis is the etiologic agent of paracoccidioidomycosis, an endemic mycosis in Latin America, and one of the major systemic mycoses prevalent in Brazil, Colombia and Venezuela. $P$. brasiliensis is a dimorphic fungus, which dimorphism from the saprophytic mycelium to the infective yeast is deeply related to virulence. As in other fungi, the phosphatase calcineurin controls the dimorphism in P. brasiliensis, and likely, other mechanisms important for infection and virulence. This study characterized the gene structure and expression of genes that code for subunits $\mathrm{A}(\mathrm{PbCNA})$ and $\mathrm{B}(\mathrm{PbCNB})$ of calcineurin of $P$. brasiliensis isolate PB18 as part of the effort to verify the role of the $\mathrm{Ca}^{2+} /$ calmodulin/calcineurin in dimorphic transition, growth and metabolism of this fungus. The nucleotide sequence of $P b C N A$ contains an ORF of 1802 bp divided into 4 exons, which codes for a $61.6 \mathrm{kDa}$ protein of 536 aa in lenght. PbCNB comprises an ORF of $862 \mathrm{bp}$ also divided into 4 exons, coding for a protein composed of 201 aa and molecular mass of $19.6 \mathrm{kDa}$. PbCNA, and to a lesser extent $P b C N B$, showed increased levels of transcripts in the early stages (up to 1 hour) of the mycelium-yeast transition $(\mathrm{M}-\mathrm{Y})$ induced by increase in temperature, suggesting the need for calcineurin to trigger the dimorphic transition in response to heat shock. The transcripts of both genes were more elevated in yeast than in mycelia, which might be related to increased virulence of the forms that grow at $37^{\circ} \mathrm{C}$. Genes which products could interact with calcineurin were searched in the transcriptome of PB18 isolate through computational tools, which provided an untreated result of 841 genes. The profiles of expression during $M-Y$ dimorphism of three of them, COX1, CCH1 and $A O X 1$, followed the profiles of $P b C N A$ and $P b C N B$. Assays of heterologous expression of PbCNA did not functionally complement mutants of Saccharomyces cerevisiae in which the two copies of subunit A of calcineurin has been deleted. In conclusion, the characterization of subunits $A$ and $B$ genes of calcineurin and their adjacent regions, their expression profiles analysis in the two different forms and over dimorphism, as well as analysis of heterologous expression may contribute to the understanding of the biochemical processes involved in morphological transition and developing of pathogenicity and virulence of $P$. brasiliensis.

Key words: Paracoccidioides brasiliensis. Dimorphism. Calcineurin. Gene expression. 
INTRODUÇÃO 


\section{INTRODUÇÃO}

\subsection{Paracoccidioides brasiliensis e Paracoccidioidomicose}

O fungo Paracoccidioides brasiliensis é o agente etiológico da paracoccidioidomicose, uma micose sistêmica profunda endêmica da América Latina, e uma das principais micoses sistêmicas prevalentes no Brasil, Colômbia e Venezuela (SAN-BLAS, 2002). É encontrado em todos os países da América Latina, exceto Chile e Caribe, sendo que a prevalência varia entre os países, como mostra o mapa da Figura 1.

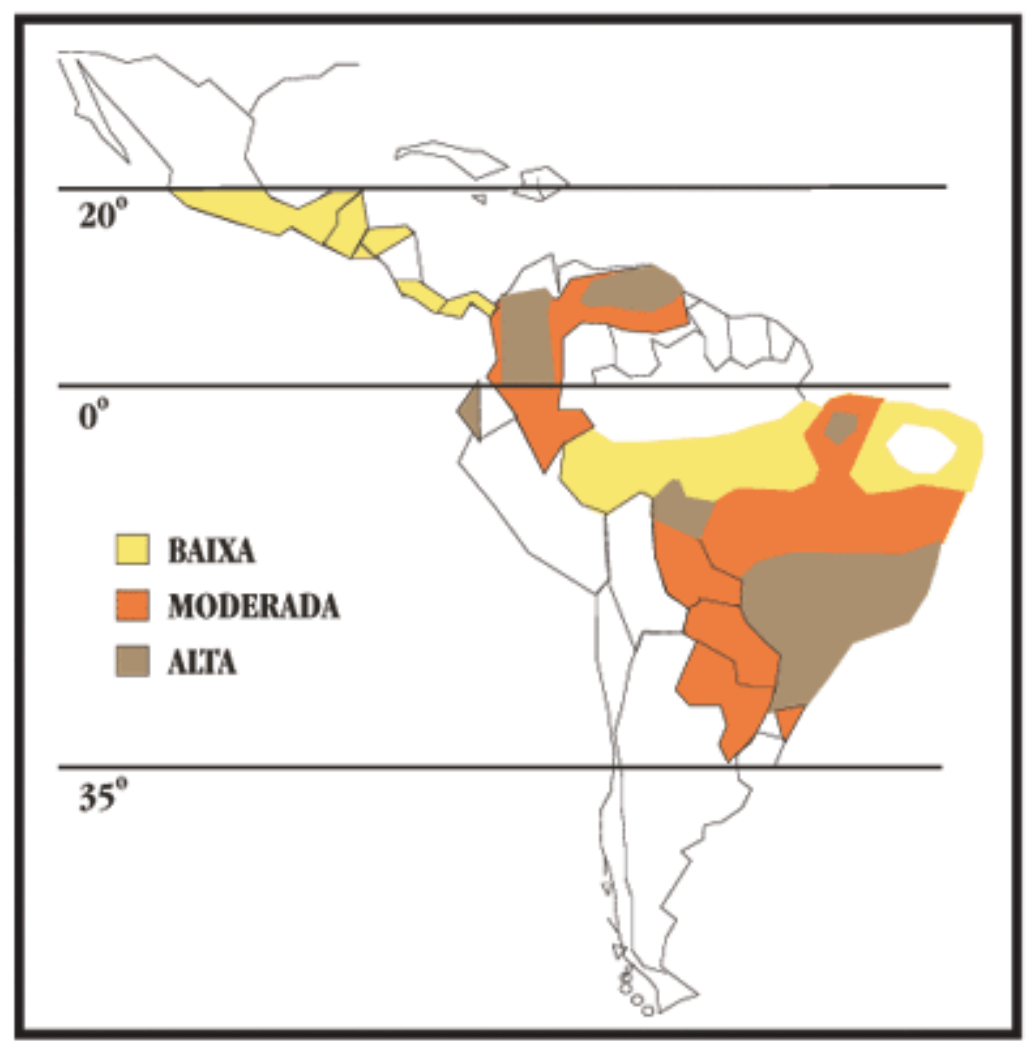

Figura 1 - Distribuição geográfica da Paracoccidioidomicose no Brasil de acordo com a incidência. FONTE: SHIKANAI-YASUDA et al., 2006

Trata-se de um fungo dimórfico encontrado na forma de micélio no meio ambiente, sua forma infectante e na forma de levedura multinucleada, sua forma patogênica e parasitária, no hospedeiro humano. Quando observadas ao microscópio, na fase leveduriforme, caracterizam-se pela presença de células esféricas ou ovais, com paredes bem definidas, bi-refringentes e apresentam um brotamento multipolar característico do 
tipo "roda de leme", enquanto na fase miceliana dependendo das condições de cultivo, apresenta hifas longas e delgadas (SAN-BLAS, 2002).

A paracoccidioidomicose ocorre com maior prevalência em indivíduos do sexo masculino com idade entre 30 e 50 anos, trabalhadores rurais e operários da construção civil, que apresentam baixo nível sócio-econômico e um elevado grau de desnutrição, alcoolismo e tabagismo crônico. A menor prevalência da doença em mulheres pode ser explicada pelo efeito protetor do hormônio feminino $17-\beta$-estradiol, que reconhece uma proteína receptora presente na fase miceliana do fungo capaz de bloquear a transformação de micélio para levedura (LOOSE et al., 1983; RESTREPO et al., 1984; MARTINEZ; MOYA, 1992; SAN-BLAS et al., 2002; SANTOS et al., 2003).

A infecção ocorre através da inalação dos propágulos (microconídios) de $P$. brasiliensis pelo indivíduo. No pulmão o choque de temperatura leva ao início da transição para levedura, enquanto ocorre fagocitose pelos macrófagos alveolares e subseqüente inflamação no parênquima pulmonar. É nessa fase que pode haver disseminação hematogênica para outros locais do corpo dos indivíduos susceptíveis. Se o hospedeiro encontra-se em bom estado de saúde, no entanto, os focos da infeç̧ão pulmonar começam a regredir espontaneamente com o estabelecimento da imunidade celular. As lesões tornam-se residuais, porém, podem abrigar fungos viáveis latentes (LACAZ, 1994).

O diagnóstico da paracoccidioidomicose é principalmente realizado através da observação da ocorrência do $P$. brasiliensis através do microscópio em material clínico, em busca de leveduras com parede bi-refringente e múltiplos brotamentos, para posterior isolamento em cultura. O diagnóstico através de ensaios imunológicos também é possível, e pode ser utilizado tanto para a deteç̧ão inicial quanto para o acompanhamento da doença. A especificidade dos testes sorológicos depende do antígeno utilizado. Em um estudo epidemiológico sobre paracoccidioidomicose utilizando o antígeno gp43, componente antigênico descrito em P. brasiliensis, foram analisados 118 operários no noroeste do Paraná e foi revelado que $43 \%$ dos operários apresentavam anticorpos para este antígeno (FORNAJEIRO et al., 2005). A resposta imune celular é a principal forma de resposta imune que medeia defesa dos hospedeiros contra a infecção pelo $P$. brasiliensis, enquanto as formas mais graves da doença estão associadas a níveis altos de anticorpos e ativação 
policlonal de linfócitos B (ARANGO; YARZÁBAL, 1982). A resposta imune humoral governada por linfócitos T "helper" 2 (Th2), conduzem a uma doença mais grave ao contrário daquelas associadas com a ativação da imunidade celular, comandada pelos linfócitos T "helper" 1 (Th1), que levam a uma patologia menos grave (MUNK et al., 1994).

Como a paracoccidioidomicose não é uma doença de notificação compulsória nacional e apenas recentemente se propôs que fosse incluída na lista de doenças de notificação compulsória do Estado de São Paulo, os dados epidemiológicos são incompletos, pois se baseiam apenas em menções em registros de óbito (COUTINHO et al., 2002; SANTO, 2008). Esses dados apontam para aproximadamente 200 mortes por ano. No entanto, estima-se que na América Latina 10 milhões de pessoas possam estar atualmente infectadas por este fungo (RESTREPO et al., 2001), sendo que se acredita que $80 \%$ delas estejam no Brasil.

Durante a primeira metade do desenvolvimento desse trabalho a composição genética de $P$. brasiliensis era pouco conhecida e as informações sobre a dimensão do genoma e organização cromossômica eram escassas. Sabia-se que as hifas unicelulares e os propágulos possuem um único núcleo e que se tornam multinucleados durante o processo de dimorfismo (MCEWEN et al., 1987). Experimentos de eletroforese em gel de campo pulsado (PFGE) e microscopia confocal de fluorescência foram utilizados no passado para estimar o conteúdo de DNA e a ploidia de P. brasiliensis. O tamanho do genoma estimado pela PFGE foi de cerca de $30 \mathrm{Mb}$ e os resultados obtidos por microscopia confocal de fluorescência forneceram evidências de que, dependendo do isolado, este poderia ser haplóide, diplóide ou mesmo aneuplóide (CANO et al., 1998). A densidade de genes, determinada através do seqüenciamento de trechos genômicos mostrou ser de um gene por 3,5 a 4,5 kbp, sugerindo um total de 7500 a 9000 genes presentes no genoma. O padrão eletroforético revelou polimorfismos cromossômicos no fungo, o qual apresentou 4 a 5 moléculas de DNA cromossômico de acordo com o isolado analisado, com tamanhos variando entre 2 a $10 \mathrm{Mb}$ (FEITOSA et al., 2003). No entanto, durante o desenvolvimento deste trabalho, o Broad Institute (MIT e Harvard) realizou o seqüenciamento completo dos genomas de três isolados de $P$. brasiliensis e ficou mostrado que o tamanho dos genomas variam entre 29.06 a $32.94 \mathrm{Mb}$ e que a quantidade de genes prevista através de técnicas 
computacionais está entre 7,875 e 9,132. O número de cromossomos não estava determinado, até o fechamento desse trabalho, para todos os três isolados. Essa informação existe apenas para o isolado $\mathrm{Pb} 18$, sendo um total de cinco cromossomos.

Por um longo período o $P$. brasiliensis foi considerado um fungo imperfeito, pois apenas é conhecido o seu estágio anamórfico, mas não sua fase sexual ou teleomórfica. Recentemente, com o avanço das técnicas moleculares, este fungo foi colocado na família Onygenaceae (Ordem Onygenales, Ascomycota), em um grupo comum com Blastomyces dermatitidis, Coccidioides immitis e Histoplasma capsulatum. Mais recentemente, um clado distinto dos Onygenaceae tem sido proposto como uma nova família (Onygenales, Ajellomycetaceae) de forma a compreender o grupo monofilético Ajellomyces, que inclui os gêneros imperfeitos Blastomyces, Emmonsia, Histoplasma e Paracoccidioides (BAGAGLI et al., 2008).

Desde a sua descoberta que o $P$. brasiliensis vem sendo considerado como uma única espécie dentro de seu gênero com base em sua morfologia, mas estudos moleculares recentes sugerem que o gênero Paracoccidioides compreenda mais espécies, uma vez que dentre os isolados, existe grande variabilidade genética. Estudos recentes que analisaram grande número de isolados em busca de espécies crípticas e possível recombinação genética através da análise de diversas regiões codificantes e não codificantes do genoma nuclear agruparam os isolados em três possíveis espécies distintas, que estão sendo chamadas de S1, PS2 e PS3, e mais recentemente apontaram o isolado Pb01 como outra espécie separada das outras três (BAGAGLI et al., 2008; CARRERO et al., 2008; MATUTE et al., 2006). Mais recentemente, 17 isolados com semelhanças ao Pb01 foram agrupados através de métodos de reconhecimento de espécies através de concordância genealógica (GCPSR). Este grupo apresentou divergências aos grupos S1, PS2 e PS3, de modo que podem ser considerados, de forma consistente com GCPSR, representantes de uma possível quarta espécie (Figura 2) (TEIXEIRA et al., 2009). 

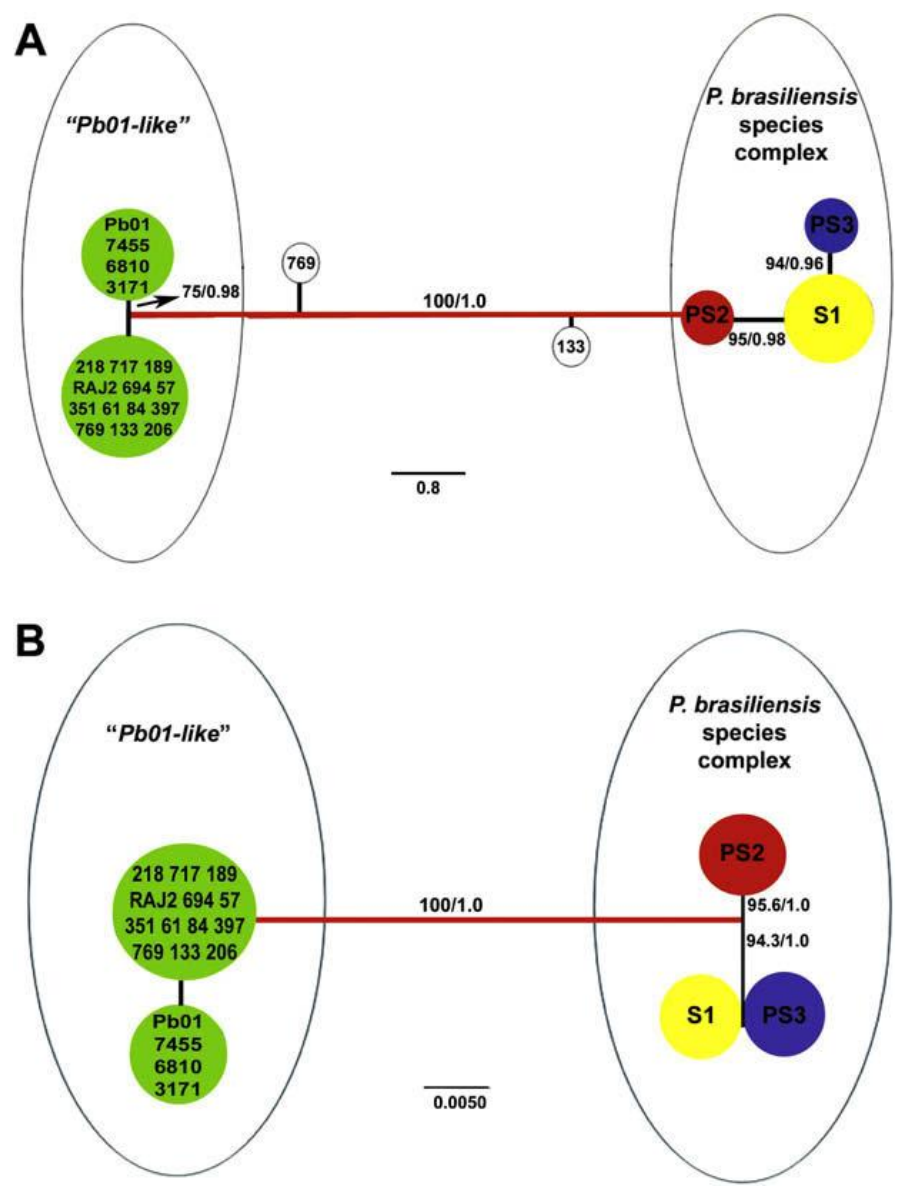

Figura 2 - Filogramas consensuais, pelo método de Bayes, não enraizados mostrando a relação entre os isolados das três espécies filogenéticas S1, PS2, PS3 e o grupo de isolados semelhante ao Pb01 (Pb01-like). (A) Oito loci concatenados, compreendendo 3.565 nucleotídeos, a partir de dados das regiões gênicas: $f k s-e x o n 2, f k s-$ exon3, chs2-exon1, chs2-exon2-4, gp43-promotor-exon1, gp43-exon2, e ARF-tubulina. (B) Cinco loci concatenados, compreendendo 1662 nucleotídeos, a partir de dados das regiões gênicas: hidrophobina30UTR, hidrophobina-50UTR, Hsp70-50UTR e intron1, kex in tron1 ITS e 1/2 + 5.8S. Os ramos com valores de bootstrap e probabilidade abaixo de $70 \%$ e 0,95 , respectivamente, e que portanto, não satisfazem os critérios GCPSR, não foram mostrados. A escala de cada árvore significa o nú mero de substituições por sítio analisadas.

FONTE: TEIXEIRA et al., 2009

\subsection{Fungos dimórficos}

Certos fungos clinicamente importantes expressam-se fenotipicamente através de duas morfologias distintas, que se correlacionam com os modos de crescimento saprofítico e parasitário. Esses são chamados de fungos dimórficos. Alguns pesquisadores restringem esse termo apenas para patógenos que crescem como micélio em temperatura ambiente e como levedura no tecido animal ou a $37{ }^{\circ} \mathrm{C}$. Em contrapartida, outros utilizam esse termo para 
qualquer fungo dimórfico que pode existir com os dois fenótipos diferentes, independentemente de ser patogênico.

A transição morfológica dos fungos é uma característica genética freqüentemente associada à sua patogenicidade. Entre mais de 100.000 espécies diferentes de fungos, existem seis fungos dimórficos que causam doença em humanos: os ascomicetos Blastomyces dermatitidis, Coccidioides immitis, Histoplasma capsulatum, Sporothrix schenkii, Penicillium marneffei e Paracoccidioides brasiliensis (NEMECEK et al., 2006). Todos apresentam uma forma miceliana saprofítica no meio ambiente e se tornam leveduras patogênicas quando infectam o hospedeiro mamífero. Candida albicans, um patógeno oportunista mais distantemente relacionado com esses outros, apresenta polimorfismo (levedura, pseudohifa e hifa), só que a forma que causa doença é o micélio. Conforme o hospedeiro se torna imunocomprometido ou a competição com a flora local é alterada, este oportunista começa a apresentar o morfotipo de hifa. Como as lesões clínicas de $C$. albicans são muitas vezes marcadas pela presença de células de diferentes morfologias, acredita-se que todas as formas possam ser necessárias para a manutenção da infecção. Os mecanismos que regulam o dimorfismo em fungos precisam ser mais bem elucidados, já que a compreensão do controle deste parâmetro durante a adaptação para condições oferecidas pelo hospedeiro mamífero pode fornecer sugestões para a elaboração de novas propostas de tratamento e prevenção de doenças fúngicas sistêmicas (ROONEY; KLEIN, 2002).

\subsection{0 dimorfismo em Paracoccidioides brasiliensis}

A transição dimórfica de levedura para micélio, em $P$. brasiliensis, começa com brotamentos alongados que se estendem a partir da levedura. Estes brotos possuem uma mistura de características, tanto da levedura quanto do micélio. A transição de micélio para levedura começa com o alargamento dos espaços interceptais exteriores e rachaduras na parede celular da hifa. Posteriormente, os espaços interseptais tendem a se tornar redondos e se separam. De micélio para levedura, apenas poucos espaços interseptais parecem transformar-se. Enquanto a levedura é produzida por autotransformação da hifa, a formação do micélio a partir da levedura necessita da formação de uma nova estrutura e a levedura 
que a originou morre. Hifas intrahifais, hifas que se originam dentro da parede celular, são observadas durante a transformação de micélio para levedura, enquanto na transformação contrária, são observadas hifas intraleveduriformes, e ambos os elementos parecem ser responsáveis pela alta mortalidade observada durante as duas formas de transição (CARBONELL, 1969).

No $P$. brasiliensis, foi mostrado que os fungos incapazes de se diferenciarem em leveduras são também incapazes de causar doença. Isto indica que durante o processo de dimorfismo os fungos expressam fatores necessários para sobrevivência no hospedeiro, bem como outros fatores de virulência que vão garantir o sucesso da infecção e, nos indivíduos susceptíveis, contribuir para o estabelecimento da doença. De modo geral, a prevalência da paracoccidioidomicose é menor em mulheres do que em homens, numa razão de treze homens para uma mulher, devido ao efeito protetor do hormônio feminino 17 - $\beta$-estradiol, que reconhece uma proteína receptora presente na fase miceliana do fungo capaz de bloquear a transformação de micélio para levedura (RESTREPO et al, 1984). Este processo de adaptação morfofisiológica que acontece no hospedeiro no início da infecção e que leva ao dimorfismo é desencadeado por fatores intrínsecos e principalmente extrínsecos ao fungo, os quais podem ser temperatura, disponibilidade de alimento ou oxigênio (MARESCA; KOBAYASHI, 2000; SAN-BLAS et al., 2002). No caso específico do $P$. brasiliensis, o choque de temperatura de $25{ }^{\circ} \mathrm{C}$ para $37{ }^{\circ} \mathrm{C}$ é suficiente para desencadear o dimorfismo do micélio para levedura tanto in vivo quanto in vitro.

Considerando a importância do processo de transição dimórfica para a aquisição de fatores de virulência, alguns estudos têm sido realizados visando encontrar em $P$. brasiliensis genes expressos diferencialmente, bem como proteínas com atividade regulada durante a transição morfológica que correspondam a possíveis fatores de virulência, sendo por isso alvos potenciais do bloqueio da infecção pelo fungo (FELIPE et al., 2003; GOLDMAN et al., 2003; MARQUES, 2003; VENÂNCIO et al., 2002). No entanto, ainda se conhece pouco a respeito dos mecanismos bioquímicos e de sinalização celular que controlam a transição de micélio para levedura induzida pela mudança de temperatura neste fungo. Num trabalho de Felipe e colaboradores (2005) foi feita uma extensa análise do transcriptoma do $P$. brasiliensis, e foram previstas algumas vias metabólicas e de sinalização celular neste fungo 
já conhecidas para outros organismos. Entre elas as vias de sinalização por $\mathrm{Ca}^{2+} / \mathrm{calmodulina}^{2}$ que, em particular, mostraram o potencial de desempenhar um papel importante na diferenciação celular em $P$. brasiliensis. Do mesmo modo foram revelados vários componentes da via de sinalização por MAP-cinase, envolvida na manutenção da integridade celular, construção da parede celular, regulação osmótica, feromônios e acasalamento; cAMP/PKA, na regulação do desenvolvimento fúngico e virulência, além da via que envolve a calcineurina, objeto deste trabalho.

\subsection{A sinalização por calcineurina em fungos}

A calcineurina, uma fosfatase ativada por $\mathrm{Ca}^{2+} /$ calmodulina, é formada por uma subunidade catalítica, calcineurina $A$, e uma subunidade regulatória, calcineurina $B$. Todos os organismos eucarióticos possuem ao menos um gene codificando cada subunidade. Nos eucariotos inferiores a subunidade A tem massa molecular entre 57 e 71 kDa e contém um domínio catalítico similar ao de outras fosfatases de serina e treonina, além de três domínios regulatórios em sua região carboxi-terminal: um para ligação da calcineurina $B$, um para ligação da calmodulina e outro auto-inibitório, que bloqueia o sítio de ligação ao substrato quando os níveis citoplasmáticos de íons de cálcio estão baixos. A calcineurina $B$ tem entre 19 e 20 kDa e contém 4 domínios de ligação de cálcio (motivo dedos EF - "EF hands") e uma miristoilação para ligação à membrana. A ativação da calcineurina se dá quando há aumento dos níveis intracelulares de $\mathrm{Ca}^{2+}$, e ligação do complexo $\mathrm{Ca}^{2+} /$ calmodulina à subunidade $\mathrm{A}, \mathrm{o}$ que leva a uma alteração conformacional que expõe o sítio ativo, cessando a auto-inibição (KISSINGER et al., 1995).

$\mathrm{Na}$ levedura Saccharomyces cerevisiae, a calcineurina é necessária para a sobrevivência sob diversas situações de estresse ambiental, incluindo altas concentrações de íons $\mathrm{Na}^{+}, \mathrm{Li}^{+}, \mathrm{Mn}^{2+}$ e $\mathrm{pH}$ alcalino, além de feromônios e antifúngicos. Os alvos da calcineurina já descritos neste modelo incluem Hph1p e Hph2p, que possuem papéis na promoção do crescimento sob condições de alta salinidade, $\mathrm{pH}$ alcalino e estresse da parede celular (HEATH et al., 2004), e também $\operatorname{S} / m 1 p$ e $\operatorname{S} / m 2 p$, proteínas que estão envolvidas, junto com o complexo TORC2, na sinalização para a organização da actina no citoesqueleto durante o 
estresse (BULTYNCK et al., 2006). Há também estabelecido um papel para calcineurina na resposta a estresse do retículo endoplasmático (RE). Leveduras que tiveram a atividade da calcineurina bloqueada são sensíveis à exposição prolongada a tunicamicina, um inibidor da glicosilação de proteína no RE (BONILLA et al., 2002). Além disso, foi mostrado que a calcineurina exerce um controle mais amplo das funções de resposta a estresses ambientais regulando a expressão de genes envolvidos com sobrevivência através da desfosforilação no citoplasma e conseqüente acúmulo no núcleo do fator de transcrição $\operatorname{crz1p} / T c n 1 p$ (STATHOPOULOS; CYERT, 1997), homólogo ao NFAT de humanos que, em células T, controla a ativação de genes de resposta imune e de homeostase de cálcio.

Assim como em S. cerevisiae, fungos patogênicos para humanos, como Cryptococcus neoformans e Candida albicans dependem da sinalização por calcineurina para responder a estresses ambientais e aqueles causados por antifúngicos, sendo a calcineurina considerada um fator de virulência para estes fungos. Foi mostrado que mutantes de calcineurina apresentam virulência significativamente reduzida e que a calcineurina também controla morfogênese, viabilidade e ciclo celular. $O$ crescimento do fungo patogênico oportunista $C$. neoformans é sensível à aos inibidores de calcineurina CsA e FK506, a $37{ }^{\circ} \mathrm{C}$, mas não a temperatura ambiente, e que cepas nas quais a calcineurina foi deletada são viáveis, porém não sobrevivem in vitro em condições que simulam o interior do hospedeiro $\left(37{ }^{\circ} \mathrm{C}, 5 \% \mathrm{de}\right.$ $\mathrm{CO}_{2}$ ou $\mathrm{pH}$ alcalino) e perdem a patogenicidade em um modelo animal de meningite criptocócica (ODOM et al., 1997). Em C. albicans mutantes de calcineurina apresentaram virulência significativamente reduzida em um modelo murino de infecção sistêmica e são incapazes de sobreviver em soro. Em contraste com o seu papel em $C$. neoformans, a calcineurina não é necessária para sobrevivência a $37^{\circ} \mathrm{C}$ por C. albicans (BLANKENSHIP et al., 2003), o que mostra que apesar da função da calcineurina ser compartilhada mesmo em fungos distantemente relacionados, os mecanismos de ação podem divergir.

Homólogos do fator de transcrição ativado pela calcineurina $\operatorname{Crz1p}$ de fungos se mostraram igualmente importantes para o crescimento, patogenicidade e virulência de fungos. A inativação do $\operatorname{CrzA}$, um homólogo de $\operatorname{Crz1p}$ no fungo patogênico filamentoso Aspergillus fumigatus resultou em uma cepa com deficiências significativas na germinação de conídios, no crescimento polarizado das hifas, na estrutura da parede celular, e 
desenvolvimento assexuado que são semelhantes aos defeitos observados em mutantes de calcineurina deste fungo. Tal como em linhagem deficiente de calcineurina, a deleção de CrzA tornou este fungo incapaz de causar doença em modelo murino de aspergilose pulmonar invasiva (SORIANI et al., 2008). Em C. albicans a deleção de CRZ1 torna este fungo hipersensível a pH alcalino e estresses de membrana, incluindo os causados por SDS (dodecil-sulfato de sódio) e antifúngicos da família dos azoles (SANTOS; DE LARRINOA, 2005).

\subsection{0 papel da calcineurina em Paracoccidioides brasiliensis}

Como ainda não existem disponíveis ferramentas para a manipulação genética de $P$. brasiliensis, inibidores de calcineurina podem ser empregados para verificar o papel desta neste fungo. Drogas inibidoras frequentemente utilizadas para este fim incluem a ciclosporina A (CSA) e FK506. A ciclosporina A é uma droga imunossupressora obtida originalmente do fungo Beauveria nivea, isolado de solo norueguês, que é amplamente utilizada para evitar a rejeição em transplante de órgãos e sua descoberta foi um marco na história da medicina (STARZL et al., 1981). Esta droga se complexa com ciclofilinas, proteínas com atividade de cis-trans isomerase presentes nos eucariotos, para se ligar a uma superfície que conjuga as duas subunidades da calcineurina, próximo ao sítio catalítico, de forma a impedir sua atividade fosfatásica (HUAl et al., 2002). FK506 foi isolado da bactéria Streptomyces tsukubaensis de solo japonês. Assim como CsA, é outro imunossupressor que se liga a uma ciclofilina (FKBP) para inibir a atividade da calcineurina (LIU et al., 2009; WANG; HEITMAN, 2005).

Dados publicados pelo nosso grupo (CAMPOS et al., 2008 - ANEXO 1), mostraram que a inibição da calcineurina por CsA é mais eficiente do que a induzida por FK506 e isso foi explicado através da medição da atividade citoplasmática de prolina isomerase que indicou níveis de ciclofilinas inibidas por CsA endógena superiores aos daquelas inibidas por FK506. O uso de CsA causou a diminuição da proliferação celular e bloqueou a transição de micélio para levedura do $P$. brasiliensis, o que indica que este fungo apresenta um sistema de ativação da calcineurina com função similar ao observado em $C$. neoformans e $C$. albicans no 
que diz respeito ao controle do dimorfismo por estresse térmico. Dados do mesmo artigo revelaram que a calcineurina é ativada precocemente após o choque térmico quando micélios são colocados a $37{ }^{\circ} \mathrm{C}$. A ativação da calcineurina segue a elevação dos níveis de cálcio intracelulares e, em micélios de $P$. brasiliensis, os níveis de cálcio intracelular aumentam imediatamente após o choque de temperatura que induz o dimorfismo. $\mathrm{O}$ uso dos quelantes de cácio BAPTA (intracelular) e EGTA (extracelular) inibiu a transição, enquanto a adição de cálcio a acelerou. No nível transcricional, o homólogo em $P$. brasiliensis do canal de cálcio de membrana plasmática $\mathrm{CCH} 1$ parece ser controlado por calcineurina. A presença de CsA diminuiu os níveis de cálcio intracelular na fase de levedura, fase em que a calcineurina é aparentemente mais abundante. Quando micélios são transferidos para temperatura de cultivo de $37{ }^{\circ} \mathrm{C}$, observa-se um pico de expressão de $\mathrm{CCH} 1$ logo no após o estímulo térmico da transição de micélio para levedura, e um incremento deste estimulo pela ciclosporina A.

Embora ainda não se tenha disponível ferramentas moleculares de transformação do P. brasiliensis que permitam "knockout" ou silenciamento gênico como rotina de laboratório, existe relato de sucesso de introdução de plasmídeos nesse fungo, bem como de silenciamento gênico (ALMEIDA et al., 2007), e de acordo com Morais e Nóbrega

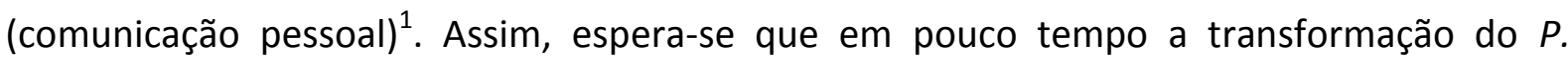
brasiliensis seja uma técnica usual dos laboratórios de pesquisa. Com a finalidade maior de se obter e conhecer os genes de ambas as subunidades da calcineurina para uso em futuros ensaios de transformação do fungo, neste trabalho foi caracterizada a estrutura gênica e expressão dos genes que codificam para as subunidades $A$ e $B$ da calcineurina de $P$. brasiliensis como parte do esforço para verificar o papel do sistema $\mathrm{Ca}^{2+} /$ calmodulina/calcineurina na transição dimórfica, crescimento e metabolismo do fungo P. brasiliensis. Acreditamos que a caracterização dos genes das subunidades $A$ e $B$ da calcineurina, sua expressão nas diferentes formas e ao longo do dimorfismo, assim como o a análise de suas regiões adjacentes, possam também contribuir para o entendimento dos processos bioquímicos envolvidos na transição morfológica e no desenvolvimento da patogenicidade e virulência do P. brasiliensis. Acreditamos ainda que a definição da calcineurina como importante fator de virulência para o P. brasiliensis possa permitir o estabelecimento de novas abordagens terapêuticas e preventivas contra este fungo parasita. 
CONCLUSÕES 


\section{CONCLUSÕES}

A partir dos resultados obtidos neste trabalho foi possível inferir, de acordo com cada objetivo:

OBJETIVO 1: Clonagem, seqüenciamento e análise dos genes da calcineurina A (subunidade catalítica) e da calcineurina B (subunidade regulatória) de Paracoccidioides brasiliensis.

a) o genoma de Paracoccidioides brasiliensis apresenta um único gene para cada uma das subunidades de $P b C N A$ e $P b C N B$;

b) estes estão localizados em cromossomos distintos no isolado $\mathrm{Pb} 18, \mathrm{PbCNA}$ no cromossomo 1 e $P b C N B$ no cromossomo 5;

c) quando analisados em função da similaridade das seqüências nucleotídicas e composição do locus gênico entre os diferentes isolados, Pb01 foi o mais divergente.

OBJETIVO 2: Caracterização estrutural dos genes da calcineurina A e B e de suas regiões flanqueadoras.

a) tanto $P b C N A$ quanto $P b C N B$ encontram-se divididos em 4 exons;

b) o tamanho e a localização dos exons e introns são conservados entre outros fungos filamentosos;

c) a estrutura genômica ou genes das regiões adjacentes a $P b C N A$ e $P b C N B$ são conservadas entre os isolados de $P$. brasiliensis.

OBJETIVO 3: Análise das seqüências peptídicas previstas de ambos os genes e busca de domínios importantes para a atividade da calcineurina.

a) a calcineurina A de $P$. brasiliensis possui massa molecular igual a $61,6 \mathrm{kDa}$;

b) a calcineurina $A$ de $P$. brasiliensis possui um domínio catalítico da família de serina/treonina fosfatases PP2Ac; um domínio de ligação à calcineurina B; um domínio de ligação a calmodulina e; um domínio auto inibitório;

c) a calcineurina B de $P$. brasiliensis possui massa molecular igual a $19,6 \mathrm{kDa}$; 
d) a calcineurina B de $P$. brasiliensis quatro domínios de ligação a íons $\mathrm{Ca}^{2+}$ (EF-hands).

OBJETIVO 4: Caracterização da expressão dos genes de calcineurina A e B nas duas formas e durante a transição dimórfica.

a) tanto $P b C N A$ quanto $P b C N B$ apresentaram aumento dos níveis de transcritos nas fases inicias (até 1 hora) da transição M-L;

b) níveis dos transcritos, tanto de $P b C N A$ quanto de $P b C N B$, se apresentaram mais elevados em leveduras do que em micélios.

OBJETIVO 5: Análise de expressão de genes que codificam possíveis alvos da calcineurina.

a) os perfis expressão de COX1, CCH1 e AOX1 durante o dimorfismo de micélio para levedura acompanham os níveis dos transcritos de $\mathrm{PbCNA}$;

b) o inibidor de calcineurina antecipou a expressão de COX1 e CCH1 no processo de dimorfismo, bem como bloqueou a expressão em leveduras.

OBJETIVO 6: Complementação funcional de linhagem de Saccharomyces cerevisiae deficiente de calcineurina A com o gene de Paracoccidioides brasiliensis.

PbCNA não é capaz de complementar funcionalmente a linhagem de $S$. cerevisiae MCY300-2 nula para as duas isoformas da calcineurina $\mathrm{A}$ (CNA1 e CMP1).

OBJETIVO 7: Complementação funcional de linhagem de Aspergillus nidulans deficiente de calcineurina A com o gene de Paracoccidioides brasiliensis.

Os resultados referentes a esse objetivo ainda não foram conclusivos. 
REFERÊNCIAS 


\section{REFERÊNCIAS*}

AKHTER, S. et al. Role of Alternative Oxidase Gene in Pathogenesis of Cryptococcus neoformans . Infection and Immunity, v. 71, n. 10, p. 5794-5802, 2003.

ALMEIDA, A. J. et al. Towards a molecular genetic system for the pathogenic fungus Paracoccidioides brasiliensis. Fungal Genetics and Biology: FG \& B, v. 44, n. 12, p. 13871398, 2007.

ALTSCHUL, S. F.; GISH, W.; MILLER, W.; MYERS, E. W.; LIPMAN, D. J. Basic local alignment search tool. Journal of Molecular Biology, v. 215, n. 3, p. 403-10, 1990.

ARAMBURU, J. et al. Affinity-Driven Peptide Selection of an NFAT Inhibitor More Selective Than Cyclosporin A. Science, v. 285, n. 5436, p. 2129-2133, 1999.

ARANGO, M.; YARZÁBAL, L. T-cell dysfunction and hyperimmunoglobulinemia $E$ in paracoccidioidomycosis. Mycopathologia, v. 79, n. 2, p. 115-123, 1982.

BAGAGLI, E.; THEODORO, R. C.; BOSCO, S. M. G.; MCEWEN, J. G. Paracoccidioides brasiliensis: phylogenetic and ecological aspects. Mycopathologia, v. 165, n. 4-5, p. 197-207, 2008.

BANDEIRA, S. C.; NÓBREGA, M. P. Characterization of Paracoccidioides brasiliensis COX9, COX12, and COX16 respiratory genes. Mycological Research, v. 112, n. 12, p. 1414-1420, 2008.

BLANKENSHIP, J. R. et al. Calcineurin is essential for Candida albicans survival in serum and virulence. Eukaryotic Cell, v. 2, n. 3, p. 422-30, 2003.

BONILLA, M.; NASTASE, K. K.; CUNNINGHAM, K. W. Essential role of calcineurin in response to endoplasmic reticulum stress. The EMBO Journal, v. 21, n. 10, p. 2343-2353, 2002.

BULTYNCK, G. et al. SIm1 and slm2 are novel substrates of the calcineurin phosphatase required for heat stress-induced endocytosis of the yeast uracil permease. Molecular and Cellular Biology, v. 26, n. 12, p. 4729-4745, 2006.

CAMPOS, C. B. L.; DI BENEdETTE, J. P. T.; MORAIS, F. V.; OVALLE, R.; NOBREGA, M. P. Evidence for the Role of Calcineurin in Morphogenesis and Calcium Homeostasis during Mycelium-to-Yeast Dimorphism of Paracoccidioides brasiliensis. Eukaryotic Cell, v. 7, n. 10, p. 1856-1864, 2008.

CANO, M. I. et al. Electrophoretic karyotypes and genome sizing of the pathogenic fungus Paracoccidioides brasiliensis. Journal of Clinical Microbiology, v. 36, n. 3, p. 742-747, 1998.

CARBONELL, L. M. Ultrastructure of Dimorphic Transformation in Paracoccidioides brasiliensis. Journal of Bacteriology, v. 100, n. 2, p. 1076-1082, 1969.

CARRERO, L. L. et al. New Paracoccidioides brasiliensis isolate reveals unexpected genomic variability in this human pathogen. Fungal Genetics and Biology, v. 45, n. 5, p. 605-612, 2008. 
CHANG, C. D. et al. Molecular cloning and characterization of the promoter region of the calcineurin A alpha gene. Biochemical Journal, v. 288, n. Pt 3, p. 801-805, 1992.

COHEN, P.; KLUMPP, S.; SCHELLING, D. L. An improved procedure for identifying and quantitating protein phosphatases in mammalian tissues. FEBS Letters, v. 250, n. 2, p. 596600, 1989.

COUTINHO, Z. F. et al. Paracoccidioidomycosis mortality in Brazil (1980-1995). Cadernos de Saúde Pública, v. 18, p. 1441-1454, 2002.

CYERT, M. S.; KUNISAWA, R.; KAIM, D.; THORNER, J. Yeast has homologs (CNA1 and CNA2 gene products) of mammalian calcineurin, a calmodulin-regulated phosphoprotein phosphatase. Proceedings of the National Academy of Sciences of the United States of America, v. 88, n. 16, p. 7376-7380, 1991.

DENG, L. et al. Real-time monitoring of calcineurin activity in living cells: evidence for two distinct Ca2+-dependent pathways in fission yeast. Molecular Biology of the Cell, v. 17, n. 11, p. 4790-4800, 2006.

FEITOSA, L. D. S. et al. Chromosomal polymorphism, syntenic relationships, and ploidy in the pathogenic fungus Paracoccidioides brasiliensis. Fungal Genetics and Biology, v. 39, n. 1, p. 60-69, 2003.

FELIPE, M. S. S. et al. Transcriptome characterization of the dimorphic and pathogenic fungus Paracoccidioides brasiliensis by EST analysis. Yeast, v. 20, n. 3, p. 263-71, 2003.

FELIPE, M. S. S. et al. Functional genome of the human pathogenic fungus Paracoccidioides brasiliensis. FEMS Immunology and Medical Microbiology, v. 45, n. 3, p. 369-81, 2005.

FERREIRA, M. E. D. S. et al. Functional characterization of the Aspergillus fumigatus calcineurin. Fungal Genetics and Biology, v. 44, n. 3, p. 219-230, 2007.

FORNAJEIRO, N.; MALUF, M. L. F.; TAKAHACHI, G.; SVIDZINSKI, T. I. E. Inquérito epidemiológico sobre a paracoccidioidomicose utilizando a gp43 em dois municípios do noroeste do Paraná, Brasil. Revista da Sociedade Brasileira de Medicina Tropical, v. 38, p. 191-193, 2005.

GATTIKER, A.; GASTEIGER, E.; BAIROCH, A. ScanProsite: a reference implementation of a PROSITE scanning tool. Applied Bioinformatics, v. 1, n. 2, p. 107-8, 2002.

GOLDMAN, G. H.; MARQUES, E. D. R.; RIBEIRO, D. C. D.; et al. Expressed sequence tag analysis of the human pathogen Paracoccidioides brasiliensis yeast phase: identification of putative homologues of Candida albicans virulence and pathogenicity genes. Eukaryotic Cell, v. 2 , n. 1, p. $34-48,2003$.

GUERINI, D. Calcineurin: Not Just a Simple Protein Phosphatase. Biochemical and Biophysical Research Communications, v. 235, n. 2, p. 271-275, 1997.

HEATH, V. L.; SHAW, S. L.; ROY, S.; CYERT, M. S. Hph1p and Hph2p, Novel Components of Calcineurin-Mediated Stress Responses in Saccharomyces cerevisiae. Eukaryotic Cell, v. 3, n. 3, p. 695-704, 2004. 
HUAI, Q. et al. Crystal structure of calcineurin-cyclophilin-cyclosporin shows common but distinct recognition of immunophilin-drug complexes. Proceedings of the National Academy of Sciences of the United States of America, v. 99, n. 19, p. 12037-12042, 2002.

KÄFER, E. Meiotic and mitotic recombination in Aspergillus and its chromosomal aberrations. Advances in Genetics, v. 19, p. 33-131, 1977.

KISSINGER, C. R. et al. Crystal structures of human calcineurin and the human FKBP12-FK506calcineurin complex. Nature, v. 378, n. 6557, p. 641-4, 1995.

KRAUS, P. R. et al. Identification of Cryptococcus neoformans Temperature-Regulated Genes with a Genomic-DNA Microarray . Eukaryotic Cell, v. 3, n. 5, p. 1249-1260, 2004.

LACAZ CS. Paracoccidioides brasiliensis: Morphology; evolutionary cycle; maintenance during saprophytic life; biology, virulence, taxonomy. In: FRANCO M.; LACAZ C.S.; RESTREPOMORENO A.; NEGRO G.D.; (Ed.). Paracoccidioidomycosis. Boca Raton: CRC Press, 1994. p. 13-25.

LIU, J. O.; NACEV, B. A.; XU, J.; BHAT, S. It Takes Two Binding Sites for Calcineurin and NFAT to Tango. Molecular Cell, v. 33, n. 6, p. 676-678, 2009.

LOOSE, D. S.; STOVER, E. P.; RESTREPO, A.; STEVENS, D. A.; FELDMAN, D. Estradiol binds to a receptor-like cytosol binding protein and initiates a biological response in Paracoccidioides brasiliensis. Proceedings of the National Academy of Sciences of the United States of America, v. 80, n. 24, p. 7659-7663, 1983.

LOPEZ, M. C.; BAKER, H. V. Understanding the Growth Phenotype of the Yeast gcr1 Mutant in Terms of Global Genomic Expression Patterns. Journal of Bacteriology, v. 182, n. 17, p. 49704978, 2000.

MAGER, W.; DE KRUIJFF, A. Stress-induced transcriptional activation. Microbiology Reviews, v. 59, n. 3, p. 506-531, 1995.

MARESCA, B.; KOBAYASHI, G. S. Dimorphism in Histoplasma capsulatum and Blastomyces dermatitidis. Contributions to Microbiology, v. 5, p. 201-16, 2000.

MARQUES, S. A. Paracoccidioidomicose: atualização epidemiológica, clínica e terapêuticaParacoccidioidomycosis: epidemiological, clinical and treatment update. Anais Brasileiros de Dermatologia, v. 78, p. 135-146, 2003.

MARTINEZ, R.; MOYA, M. J. Associação entre paracoccidioidomicose e alcoolismo. Revista de Saúde Pública, v. 26, p. 12-16, 1992.

MARTÍNEZ-PASTOR, M. T. et al. The Saccharomyces cerevisiae zinc finger proteins Msn2p and Msn4p are required for transcriptional induction through the stress response element (STRE). The EMBO Journal, v. 15, n. 9, p. 2227-2235, 1996.

MARTINS, V. et al. Mitochondrial function in the yeast form of the pathogenic fungus Paracoccidioides brasiliensis. Journal of Bioenergetics and Biomembranes, v. 40, n. 4, p. 297-305, 2008. 
MARZLUF, G. Genetic regulation of nitrogen metabolism in the fungi. Microbiology and Molecular Biology Reviews, v. 61, n. 1, p. 17-32, 1997.

MATUTE, D. R. et al. Cryptic Speciation and Recombination in the Fungus Paracoccidioides brasiliensis as Revealed by Gene Genealogies. Molecular Biology and Evolution, v. 23, n. 1, p. 65-73, 2006.

MCEWEN, J. G.; RESTREPO, B. I.; SALAZAR, M. E.; RESTREPO, A. Nuclear staining of Paracoccidioides brasiliensis conidia. Journal of Medical and Veterinary Mycology, v. 25, n. 5, p. 343-345, 1987.

MEDOFF, G.; PAINTER, A.; KOBAYASHI, G. S. Mycelial- to yeast-phase transitions of the dimorphic fungi Blastomyces dermatitidis and Paracoccidioides brasiliensis. Journal of Bacteriology, v. 169, n. 9, p. 4055-4060, 1987.

MIYAKE T; KONDO E; AKAGI T. Expression and Localization of the Calcium-Mobilizing Molecules, Calcineurin and NFAT in Germinal Center B Cells. J Clin Exp Hematop, v. 43, n. 1, p. 21-27, 2003.

MOLINARI-MADLUM, E. E.; FELIPE, M. S.; SOARES, C. M. Virulence of Paracoccidioides brasiliensis isolates can be correlated to groups defined by random amplified polymorphic DNA analysis. Medical Mycology, v. 37, n. 4, p. 269-276, 1999.

MORAIS, F. V.; BARROS, T. F.; FUKADA, M. K.; CISALPINO, P. S.; PUCCIA, R. Polymorphism in the Gene Coding for the Immunodominant Antigen gp43 from the Pathogenic Fungus Paracoccidioides brasiliensis. J. Clin. Microbiol., v. 38, n. 11, p. 3960-3966, 2000.

MUNK, M. E. et al. Human alpha beta and gamma delta T cells from unexposed individuals respond to protein antigens of the yeast form of Paracoccidioides brasiliensis. International Immunology, v. 6, n. 11, p. 1717-1725, 1994.

NAKAMURA, T. et al. Protein phosphatase type 2B (calcineurin)-mediated, FK506-sensitive regulation of intracellular ions in yeast is an important determinant for adaptation to high salt stress conditions. The EMBO Journal, v. 12, n. 11, p. 4063-4071, 1993.

NEMECEK, J. C.; WUTHRICH, M.; KLEIN, B. S. Global Control of Dimorphism and Virulence in Fungi. Science, v. 312, n. 5773, p. 583-588, 2006.

ODOM, A. et al. Calcineurin is required for virulence of Cryptococcus neoformans. The EMBO Journal, v. 16, n. 10, p. 2576-2589, 1997.

OSMANI, S. A.; MAY, G. S.; MORRIS, N. R. Regulation of the mRNA levels of nimA, a gene required for the G2-M transition in Aspergillus nidulans. The Journal of Cell Biology, v. 104, n. 6, p. 1495-1504, 1987.

PALLEN, C. J.; WANG, J. H. Calmodulin-stimulated dephosphorylation of p-nitrophenyl phosphate and free phosphotyrosine by calcineurin. The Journal of Biological Chemistry, v. 258, n. 14, p. 8550-8553, 1983.

PEDERSEN, A. G.; BALDI, P.; CHAUVIN, Y.; BRUNAK, S. The biology of eukaryotic promoter prediction--a review. Computers \& Chemistry, v. 23, n. 3-4, p. 191-207, 1999. 
RESTREPO, A.; MCEWEN, J. G.; CASTAÑEDA, E. The habitat of Paracoccidioides brasiliensis: how far from solving the riddle? Medical Mycology, v. 39, n. 3, p. 233-41, 2001.

ROONEY, P. J.; KLEIN, B. S. Linking fungal morphogenesis with virulence. Cellular Microbiology, v. 4, n. 3, p. 127-137, 2002.

SAMBROOK, P. J.; RUSSELL, D. W. Molecular cloning: a laboratory manual. 3.ed. New York: Cold Spring Harbor, 2001.

SAN-BLAS, G.; NIÑO-VEGA, G.; ITURRIAGA, T. Paracoccidioides brasiliensis and paracoccidioidomycosis: molecular approaches to morphogenesis, diagnosis, epidemiology, taxonomy and genetics. Medical Mycology: Official Publication of the International Society for Human and Animal Mycology, v. 40, n. 3, p. 225-42, 2002.

SAN-BLAS, N. V. Paracoccidioides brasiliensis: virulence and host response. In: CALDERONE R.A.; CIHLAR R.L. Fungal Pathogenesis: Principles and Clinical Applications. New York: CRC Press, 2002. p.205-226.

SANTO, A. H. Tendência da mortalidade relacionada à paracoccidioidomicose, Estado de São Paulo, Brasil, 1985 a 2005: estudo usando causas múltiplas de morte. Revista Panamericana de Salud Pública, v. 23, p. 313-324, 2008.

SANTOS, M.; DE LARRINOA, I. Functional characterization of the Candida albicans CRZ1 gene encoding a calcineurin-regulated transcription factor. Current Genetics, v. 48, n. 2, p. 88100. doi: 10.1007/s00294-005-0003-8, 2005.

SANTOS, W. A. D.; SILVA, B. M. D.; PASSOS, E. D.; ZANDONADE, E.; FALQUETO, A. Associação entre tabagismo e paracoccidioidomicose: um estudo de caso-controle no Estado do Espírito Santo, Brasil. Cadernos de Saúde Pública, v. 19, p. 245-253, 2003.

SHIKANAI-YASUDA, M. A.; TELLES FILHO, F. D. Q.; MENDES, R. P.; COLOMBO, A. L.; MORETTI, M. L. Consenso em paracoccidioidomicose. Revista da Sociedade Brasileira de Medicina Tropical, v. 39, p. 297-310, 2006.

SMALE, S. T. Transcription initiation from TATA-less promoters within eukaryotic proteincoding genes. Biochimica et Biophysica Acta (BBA) - Gene Structure and Expression, v. 1351, n. 1-2, p. 73-88, 1997.

SORIANI, F. M. et al. Functional characterization of the Aspergillus fumigatus CRZ1 homologue, CrzA. Molecular Microbiology, v. 67, n. 6, p. 1274-91, 2008.

STARZL, T. E.; KLINTMALM, G. B.; PORTER, K. A.; IWATSUKI, S.; SCHRÖTER, G. P. Liver transplantation with use of cyclosporin a and prednisone. The New England Journal of Medicine, v. 305, n. 5, p. 266-269, 1981.

STATHOPOULOS, A. M.; CYERT, M. S. Calcineurin acts through the CRZ1/TCN1-encoded transcription factor to regulate gene expression in yeast. Genes \& Development, v. 11, n. 24, p. 3432-3444, 1997.

TEIXEIRA, M. M. et al. Phylogenetic analysis reveals a high level of speciation in the Paracoccidioides genus. Molecular Phylogenetics and Evolution, 2009. In press. 
VENÂNCIO, E. J. et al. Identification of differentially expressed transcripts in the human pathogenic fungus Paracoccidioides brasiliensis by differential display. Medical Mycology, $\mathrm{v}$. 40, n. 1, p. 45-51, 2002.

WANG, P.; HEITMAN, J. The cyclophilins. Genome Biology, v. 6, n. 7, p. 226, 2005.

WITHEE, J. L.; SEN, R.; CYERT, M. S. Ion tolerance of Saccharomyces cerevisiae lacking the $\mathrm{Ca} 2+/ \mathrm{CaM}$-dependent phosphatase (calcineurin) is improved by mutations in URE2 or PMA1. Genetics, v. 149, n. 2, p. 865-78, 1998.

XIANG, B. et al. The catalytically active domain in the A subunit of calcineurin. Biological Chemistry, v. 384, n. 10-11, p. 1429-34, 2003.

YANG, C.; BOLOTIN, E.; JIANG, T.; SLADEK, F. M.; MARTINEZ, E. Prevalence of the initiator over the TATA box in human and yeast genes and identification of DNA motifs enriched in human TATA-less core promoters. Gene, v. 389, n. 1, p. 52-65, 2007. 